\title{
Response from the Authors Re: Letter to the Editor for Our Manuscript "Oocyte stimulation parameters influence the number and proportion of mature oocytes retrieved in assisted reproductive technology cycles"
}

\author{
Damla C. Gonullu' ${ }^{1}$ David H. McCulloh ${ }^{2} \cdot$ LeRoy G. Robinson $\mathrm{Jr}^{3} \cdot$ Cheongeun Oh$^{4} \cdot$ David L. Keefe $^{2,3}$
}

Received: 22 September 2021 / Accepted: 23 September 2021 / Published online: 1 October 2021

(c) The Author(s), under exclusive licence to Springer Science+Business Media, LLC, part of Springer Nature 2021

We thank the authors of this letter for their interest in our paper, and for their thoughtful analysis. The main conclusion of this study was that increased total daily gonadotropin dose was associated with increased immaturity. We agree that AMH and AFC both would have been helpful to include in our analysis. However, we did not have these values for the majority of patients in the study, since we seldom perform quantitative counts of AFC, and did not routinely assess AMH levels in our patients until 2016, near the end of the study period.

We agree that it would be beneficial to compare the effects of long GnRH agonist vs. GnRH antagonist stimulation protocols; however, almost $99 \%$ of the patients in this study underwent GnRH antagonist protocols. The 30 agonist cycles were a mix of long and flare cycles. Such small numbers would not permit meaningful comparison between agonist and antagonist protocols. We would like to highlight that our findings support the current literature showing that long GnRH agonist protocol requires more days of gonadotropin administration, higher cumulative dose of gonadotropin, and produce significantly

David H. McCulloh

david.mcculloh@nyulangone.org; dhmcculloh@gmail.com

1 Department of Obstetrics and Gynecology, Wayne State University School of Medicine, Detroit, MI, USA

2 NYU Grossman School of Medicine, NYU Langone Fertility Center, New York, NY 10016, USA

3 Department of Obstetrics and Gynecology, New York University Grossman School of Medicine, New York, NY, USA

4 Department of Population Health, New York University Grossman School of Medicine, New York, NY, USA higher numbers of mature oocytes, with similar cancellation rates [1-4].

\section{References}

1. Shrestha D, La X, Feng HL. Comparison of different stimulation protocols used in in vitro fertilization: a review. Ann Transl Med. 2015;3(10):137. https://doi.org/10.3978/j.issn.2305-5839.2015. 04.09 .

2. Franco JG Jr, Baruffi RL, Mauri AL, et al. GnRH agonist versus GnRH antagonist in poor ovarian responders: a meta-analysis. Reprod Biomed Online. 2006;13:618-27.

3. Malmusi S, La Marca A, Giulini S, et al. Comparison of a gonadotropin-releasing hormone $(\mathrm{GnRH})$ antagonist and $\mathrm{GnRH}$ agonist flare-up regimen in poor responders undergoing ovarian stimulation. Fertil Steril. 2005;84:402-6.

4. Xiao J, Chang S, Chen S. The effectiveness of gonadotropinreleasing hormone antagonist in poor ovarian responders undergoing in vitro fertilization: a systematic review and meta-analysis. Fertil Steril 2013;100:1594-601.e1-9.

Publisher's note Springer Nature remains neutral with regard to jurisdictional claims in published maps and institutional affiliations. 